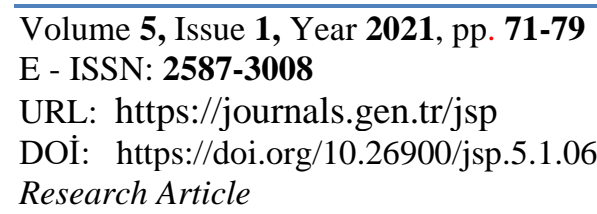

\title{
MORPHOMETRIC ANALYSIS OF THE WHITE MATTER STRUCTURES IN FEMALE MIGRAINE PATIENTS
}

\author{
Ozan TURAMANLAR ${ }^{1}$ \& Hilal GÜZEL ${ }^{2}$ \& Hayri DEMIRBAŞ ${ }^{3} \&$ \\ Furkan KAYA ${ }^{4}$ \& Abdülkadir BİLIR ${ }^{5}$ \& Seyma GÜLEN ${ }^{6}$ \& \\ Halit Hamza ÖLMEZ ${ }^{7}$ \& Muhammed EROL ${ }^{8}$ \& Elif Meryem ARDIÇ ${ }^{9}$ \& \\ Medine Feride DÜNDAR ${ }^{10}$ \& Mustafa Sait ISLIKAYE ${ }^{11}$
}

\begin{abstract}
${ }^{I}$ Assoc Prof, MD, PhD, Afyonkarahisar Health Sciences University, Faculty of Medicine, Department of Anatomy, Afyonkarahisar, TURKEY, E-mail: ozanturamanlar@hotmail.com, ORCID ID: https://orcid.org/0000-0002-0785-483X

${ }^{2}$ (Corresponding Author) Res Asst, PhD, Afyonkarahisar Health Sciences University, Faculty of Medicine, Department of Anatomy, Afyonkarahisar, TURKEY, E-mail: hilalgzl@hotmail.com, ORCID ID: https://orcid.org/0000-0001-7692-8890
\end{abstract}

${ }^{3}$ Asst Prof, MD, Afyonkarahisar Health Sciences University, Faculty of Medicine, Department of Neurology, Afyonkarahisar,TURKEY, E-mail: drhayridemirbas@gmail.com, ORCID ID: https://orcid.org/0000-0002-8339-7765

${ }^{4}$ Asst Prof, MD, Afyonkarahisar Health Sciences University, Faculty of Medicine, Department of Radiology, Afyonkarahisar,TURKEY, E-mail: furkaya157@ hotmail.com, ORCID ID: https://orcid.org/0000-0001-8619-7593

${ }^{5}$ Afyonkarahisar Health Sciences University, Faculty of Medicine, Department of Anatomy, Afyonkarahisar,TURKEY, E-mail:fztabdulkadirbilir@gmail.com, ORCID ID: https://orcid.org/0000-0003-0633-9542

${ }^{6}$ Afyonkarahisar Health Sciences University, Faculty of Medicine, Afyonkarahisar,TURKEY,E-mail: seyma.gulen.dery@gmail.com, ORCID ID: https://orcid.org/0000-0001-9020-3968

${ }^{7}$ Afyonkarahisar Health Sciences University, Faculty of Medicine, Afyonkarahisar, TURKEY, E-mail: hamza.olmez@hotmail.com, ORCID ID: https://orcid.org/0000-0002-0198-107X

${ }^{8}$ Afyonkarahisar Health Sciences University, Faculty of Medicine, Afyonkarahisar, TURKEY, E-mail: merol173401011@gmail.com, ORCID ID: https://orcid.org/0000-0003-3916-6369

${ }^{9}$ Afyonkarahisar Health Sciences University, Faculty of Medicine, Afyonkarahisar,TURKEY, E-mail: emeryemardic@gmail.com, ORCID ID: https://orcid.org/0000-0003-4836-7592 
${ }^{10}$ Afyonkarahisar Health Sciences University, Faculty of Medicine,

Afyonkarahisar, TURKEY, E-mail: fdundar.98@gmail.com, ORCID ID: https://orcid.org/0000-0002-2459-809X

${ }^{11}$ Afyonkarahisar Health Sciences University, Faculty of Medicine, Afyonkarahisar,TURKEY, E-mail: proilet.is.improh@gmail.com, ORCID ID: https://orcid.org/0000-0001-6136-1780

Received: 30 November 2020, Accepted: 29 January 2021

\section{ABSTRACT}

Migraine is a multifactorial neurovascular syndrome characterized by typical headache attacks that occur with internal and external triggering factors in individuals with genetic susceptibility. It affects more than $12 \%$ of the general population. The aim of the present study is to compare the morphometric measurements of the determined white matter structures with the control group to investigate whether there is a structural difference in white matter structures in female patients with migraine.

The width of the internal capsule parts (anterior limb, posterior limb and genu) and genu angle was evaluated through MRI. Corpus callosum related measurements were determined in the sagittal section. It was manually traced following its edge on the midsagittal slice of T1 images, where its structure appeared most remarkable. The right and left internal capsule related measurements were compared with migraine and control groups. Except the genu angle, there were statistically significant difference between all measurements and widths in the migraine group were greater than controls. No significant difference was found between the corpus callosum related measurements in the comparison of both groups.

Internal capsule consists of several essential white matter fiber bundles of the brain, and is strongly connected between a range of cortical and subcortical anatomical structures. It has a crucial importance for brain functions and it can be affected by a variety of pathologies. The corpus callosum is the main fiber tract connecting two hemispheres with extensive connections and is topographically organized. It has been investigated in several neurodegenerative diseases as a marker for cortical pathology.

Knowing the white matter structure in migraine patients, determining its prevalence, and its correlation with the severity, type and duration of migraine can give an idea to clinicians.

Keywords: Migraine, Internal Capsule, Corpus Callosum, Morphometry, MR.

\section{INTRODUCTION}

Migraine is a multifactorial neurovascular syndrome characterized by typical headache attacks that occur with internal and external triggering factors in individuals with genetic susceptibility. It affects more than $12 \%$ of the general population (Lipton et al., 2001). Migraine headache does not always occur in the same clinical form. Due to different characteristics and accompanying symptoms, migraine symptoms may vary between patients and sometimes even in the same person over time (Russel et al., 1994). Structural lesions of unknown clinical significance are frequently observed in brain Magnetic Resonance Images 
(MRI) in migraine patients (Del Zotto et al., 2008). Migraine is more common in men before puberty and in female during and after adolescence (Lipton and Bigal 2005; Lipton et al., 2007). It is most common in the 20-50 age range (Russel et al., 1994). The incidence of migraine in Turkey was found to be $16.4 \%$. It has been reported that the female to male ratio was found to be 3: 1 and it was seen in 24.6\% of female (Ertas et al., 2012).

The corpus callosum is composed of thick myelinated fibers that connect the relevant centers in the right and left brain hemispheres. This is the biggest and most important way that plays a role in the transmission of information reaching one hemisphere to the other. Corpus callosum atrophy can be seen in various neurological and psychiatric diseases ranging from Alzheimer's disease to depression (Gazzaniga, 2000; Quigley, 2003).

The internal capsule is a white matter composed of efferent and afferent fibers that extend vertically to connect some of the cortical centers to the spinal cord. It is divided into five parts which are anterior limb, genu, posterior limb, retrolentiform limb (retrolenticular part) and sublentiform limb (sublenticular part). Different fibers pass through each part of the internal capsula. Anterior thalamic radiation and frontopontine tracts from anterior limb, corticonuclear tracts from genu; retrolentiform parts and sublentiform parts are pass through the posterior limb. It is an important indicator place to identify neurological diseases at all stages of life (Turamanlar et al., 2020).

The aim of the present study is to compare the morphometric measurements of the determined white matter structures with the control group to investigate whether there is a structural difference in white matter structures in female patients with migraine.

\section{MATERIALS AND METHODS}

Our study was carried out retrospectively in the Department of Radiology and Department of Anatomy, Faculty of Medicine, Afyonkarahisar Health Sciences University. The patient group was formed with 40 female patients between the ages of 18-65 who were admitted to the neurology outpatient clinic and diagnosed with migraine. A control group was formed from 79 female individuals in the same age range who had normal findings and had not been diagnosed with migraine, who had previously undergone Magnetic Resonance Imaging (MRI) for any reason. Those who were outside the specified age range, male patients and patients with any pathology other than migraine on MRI were excluded from the study.

Images were obtained from T1 weighted both transverse and sagittal brain sections through 1.5 T MRI (Philips Medical Systems, The Netherlands). MR protocol was as follows: $\mathrm{TR}=500 \mathrm{~ms} ; \mathrm{TE}=15 \mathrm{~ms} ; \mathrm{FOV}=23 \mathrm{~cm}$, slice thickness $5 \mathrm{~mm}$; number of exitations = 2; matrix size $=256 \times 256$. Anatomical measurements were conducted on the Aquarius Workstation using the Aquarius NET program (TeraRecon Inc., USA).

The width of the internal capsule parts (anterior limb, posterior limb and genu) and genu angle was evaluated through MRI. The internal capsula related measurements were made at the level where the caudat nucleus, lentiform nucleus and thalamus were seen in the same transverse section. Measurements made bilaterally in the same section. The angle of the lateral opening of the internal capsule in the genu of the line passing through the middle of the anterior and posterior limb was evaluated. The widest parts of the internal capsule between the thalamus and the lentiform nucleus were measured (Figure 1). 


\section{Figure 1}

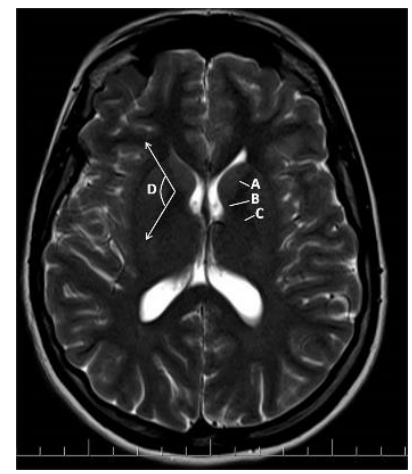

Corpus callosum related measurements were determined in the sagittal section. It was manually traced following its edge on the midsagittal slice, where its structure appeared most remarkable. Morphometric measurements were conducted according to the same methods reported previous studies (Hofer and Frahm, 2006; Unlu et al.,2014). After drawing the transverse line (AP line) that connects the extreme point of the genu with the extreme point of the splenium in the sagittal plane, a total of 5 areas were measured and evaluated through MRI (Figure 2).

Figure 2

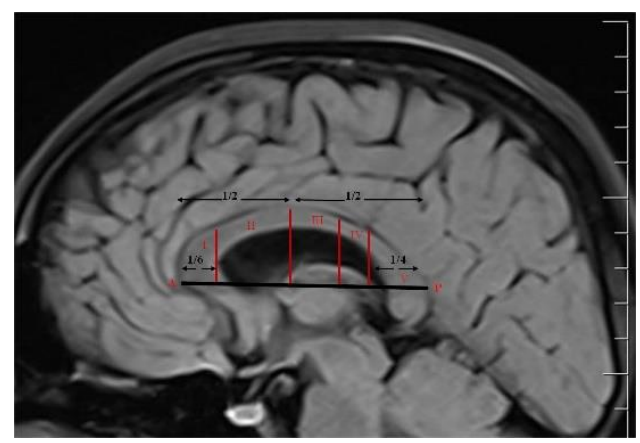

The data obtained from the study were evaluated using IBM SPSS 20.0 (IBM Statistical Package Social Science) Means, standard deviations and percentages of the data were given in statistical analysis. The distribution of the data was analyzed using the Kolmogorov-Smirnov test. Mann- Whitney U test was used for independent two group comparisons, and Kruskal Wallis test was used in multiple group comparisons. The results were evaluated at the $95 \%$ confidence interval and the significance at the $\mathrm{p}<0.05$ level.

\section{RESULTS}

40 female patients with migraine and 79 female individuals without a diagnosis of migraine were included in the study. The mean age of the migraine group was 40.65 year and the controls was 40.24 .

The mean widths of the anterior limb, genu and posterior limb were measured as 3.99 $\mathrm{mm}, 7.29 \mathrm{~mm}$ and $5.17 \mathrm{~mm}$ on the left side and $4 \mathrm{~mm}, 7.28 \mathrm{~mm}$ and $5.17 \mathrm{~mm}$ on the right side in migraine group, respectively. The mean widths of the anterior limb, genu and posterior limb were measured as $3.29 \mathrm{~mm}, 5.93 \mathrm{~mm}$ and $4.26 \mathrm{~mm}$ on the left side and $3.37 \mathrm{~mm}, 5.98$ $\mathrm{mm}$ and $4.06 \mathrm{~mm}$ on the right side in controls, respectively.

The measurements of the right and left internal capsule structures of the controls were compared, statistical difference was found only in the posterior limb width (Table 1). 
Table 1. Comparison of right and left internal capsula related measurements in controls $(\mathrm{p}<0.05)$.

\begin{tabular}{cccccccc}
\hline Controls & \multicolumn{3}{c}{ Left } & \multicolumn{3}{c}{ Right } & p \\
\hline & Min. & Max. & Mean \pm SD & Min. & Max. & Mean \pm SD & \\
Anterior limb (mm) & 1.42 & 9.37 & $3.29 \pm 1.30$ & 1.96 & 9.60 & $3.37 \pm 1.31$ & 0.63 \\
Genu (mm) & 3.21 & 7.69 & $5.93 \pm 0.84$ & 3.20 & 7.63 & $5.98 \pm 0.78$ & 0.67 \\
Posterior limb (mm) & 2.25 & 7.12 & $4.26 \pm 0.88$ & 1.96 & 6.76 & $4.06 \pm 0.94$ & $\mathbf{0 . 0 1}$ \\
Genu Angle (x/180) & 104.00 & 137.00 & $123.22 \pm 5.27$ & 105.00 & 135.50 & $123.03 \pm 5.41$ & 0.81 \\
\hline
\end{tabular}

When the same measurements were made for migraine group, no significant difference was detected (Table 2). The right and left internal capsule related measurements were compared with migraine and control groups. Except the genu angle, there were statistically significant difference between all measurements and widths in the migraine group were greater than controls (Table 3).

Table 2. Comparison of right and left internal capsula related measurements in patient group $(\mathrm{p}<0.05)$.

\begin{tabular}{lccccccc}
\hline Migraine Patients & \multicolumn{4}{c}{ Left } & \multicolumn{3}{c}{ Right } \\
\hline & Min. & Max. & Mean \pm SD & Min. & Max. & Mean \pm SD & p \\
Anterior limb (mm) & 2.02 & 6.15 & $3.99 \pm 0.82$ & 2.19 & 6.27 & $4 \pm 0.88$ & 0.67 \\
Genu (mm) & 5.71 & 9.39 & $7.29 \pm 1.02$ & 5.62 & 9.56 & $7.28 \pm 1.02$ & 0.67 \\
Posterior limb (mm) & 3.01 & 8.21 & $5.17 \pm 1.25$ & 2.95 & 8.05 & $5.17 \pm 1.24$ & 0.81 \\
Genu Angle (x/180) & 106.00 & 138.00 & $121.95 \pm 8.05$ & 104.80 & 137.00 & $122.13 \pm 7.99$ & 0.4 \\
\hline
\end{tabular}

Table 3. Comparison of right and left internal capsula related measurements patient group with migraine group $(\mathrm{p}<0.05)$.

\begin{tabular}{clccc}
\hline & Patients & Controls & \\
& & Mean \pm SD & Mean \pm SD & p \\
\hline \multirow{2}{*}{ Left } & Anterior limb $(\mathrm{mm})$ & $3.99 \pm 0.82$ & $3.29 \pm 1.30$ & $\mathbf{0 . 0 0 1}$ \\
& Genu & $7.29 \pm 1.02$ & $5.93 \pm 0.84$ & $\mathbf{0 . 0 0 1}$ \\
& Posterior limb (mm) & $5.17 \pm 1.25$ & $4.26 \pm 0.88$ & $\mathbf{0 . 0 0 1}$ \\
& Genu Angle $(\mathrm{x} / 180)$ & $121.95 \pm 8.05$ & $123.22 \pm 5.27$ & 0.22 \\
\hline \multirow{2}{*}{ Right } & Anterior limb $(\mathrm{mm})$ & $4 \pm 0.88$ & $3.37 \pm 1.31$ & $\mathbf{0 . 0 0 1}$ \\
& Genu & $7.28 \pm 1.02$ & $5.98 \pm 0.78$ & $\mathbf{0 . 0 0 1}$ \\
& Posterior limb $(\mathrm{mm})$ & $5.17 \pm 1.24$ & $4.06 \pm 0.94$ & $\mathbf{0 . 0 0 1}$ \\
& Genu Angle $(\mathrm{x} / 180)$ & $122.13 \pm 7.99$ & $123.03 \pm 5.41$ & 0.4 \\
\hline
\end{tabular}


No significant difference was found between the corpus callosum related measurements in the comparison of both groups (Table 4).

Table 4. Comparison of Corpus Callosum related measurements patient group with migraine group $(\mathrm{p}<0.05)$. (CC: Corpus Callosum)

\begin{tabular}{cccc}
\hline & $\begin{array}{c}\text { Migraine } \\
\text { Mean } \pm \text { SD }\end{array}$ & $\begin{array}{c}\text { Control } \\
\text { Mean } \pm \text { SD }\end{array}$ & $\mathbf{p}$ \\
\cline { 2 - 4 } CC 1 $\left(\mathrm{mm}^{2}\right)$ & $115.51 \pm 19.34$ & $169.54 \pm 38.23$ & 0.12 \\
CC 2 $\left(\mathrm{mm}^{2}\right)$ & $148.54 \pm 21.52$ & $147.95 \pm 28.81$ & 0.54 \\
CC 3 $\left(\mathrm{mm}^{2}\right)$ & $72.68 \pm 14.30$ & $68.51 \pm 15.22$ & 0.14 \\
CC 4 $\left(\mathrm{mm}^{2}\right)$ & $35.29 \pm 10.17$ & $35.21 \pm 9.42$ & 0.78 \\
CC 5 $\left(\mathrm{mm}^{2}\right)$ & $211.49 \pm 29.76$ & $217.29 \pm 39.41$ & 0.5 \\
CC lenght $(\mathrm{mm})$ & $67.27 \pm 5.43$ & $68.08 \pm 5.07$ & 0.72 \\
\hline
\end{tabular}

\section{DISCUSSION}

Understanding the pathophysiology of migraine has provided scientists with significant advances in recent years. According to the data of the World Health Organization (WHO), migraine is among the first 20 diseases that cause severe disability in the world (Leonardi et al., 2005). Migraine is a familial disease and is often characterized by a unilateral, throbbing headache and may begin in childhood, adolescence or early adulthood (Allan and Martin, 2011). As a result of recent researches, only vascular theory has been moved away from the pathophysiology of migraine and integrated neurovascular theory has been accepted (Evans et al., 2020).

Internal capsule consists of several essential white matter fiber bundles of the brain, and is strongly connected between a range of cortical and subcortical anatomical structures (Hyett et al., 2018). It has a crucial importance for brain functions and it can be affected by a variety of pathologies. It is important to know the morphological structure of this structure, which is affected differently by various diseases. It has been examined using various methods in many diseases (Chowdhury et al., 2010). In the present study, when the right and left internal capsule related measurements of both groups were compared, all measurements except the genu angle were found to be significantly higher in migraine patients.

The corpus callosum is the main fiber tract connecting two hemispheres with extensive connections and is topographically organized (Frazier and Hardan, 2009). It has been investigated in several neurodegenerative diseases as a marker for cortical pathology (Wiltshire et al., 2005). In this study, there was no significant difference in corpus callosum related measurements between the migraine and controls.

There are many studies examining different brain structures conducted to investigate the pathophysiology of migraine. In the study performed with Voxel-Based morphometry, it was stated that there was no significant difference between migraine patients and controls in terms of white matter volume or concentration (Matharu et al., 2003). In a 9-year prospective study to investigate the relationship between migraine and brain structure and function, it was shown that only female patients had higher prevalence and deeper white matter hyperintensities than controls, not male patients (Palm-Meinders et al., 2012). In a study evaluating the risk of infarction in certain regions of the brain, it was found that infarctions in the cerebellum were more common in female with migraine with aura than controls, with no 
difference between men with migraine and controls (Scher et al., 2009). One meta-analysis demonstrated that migraine patients were more likely having white matter abnormalities on MRI than controls (Swartz and Kern, 2004).

Recent studies have shown a direct relationship between chronic strokes and white matter lesions in patients with migraine (Over et al., 2007). Under the age of 40, migrainous infarcts are estimated at 1.4-14\%. According to studies, the incidence of stroke due to brain infarctions increases in migraine (Chang et al., 1999). Additionally, sex differences seem to play an important role because progression of deep white matter hyperintensities was only found in women. The relationship between migraine and ischemic stroke has been known for many years, based on the results of many studies on this subject, and migraine has been accepted as a risk factor for stroke (Buring et al., 1995; Longstreth et al., 1996). The brain damage seen in patients with migraine is related to the frequency of migraine attacks and the duration of the disease, and it is claimed that this damage occurs about fifteen years after the onset of the disease (Schmitz et al., 2008).

Some limitations of this study should be considered when interpreting our findings. For example, we did not divide patients with migraine into subgroups and our sample was relatively small. Knowing the white matter structure in migraine patients, determining its prevalence, and its correlation with the severity, type and duration of migraine can give an idea to clinicians. In our study, the capsula interna structures were found to be more enlarged in patients with migraine than in normal individuals. Does this enlargement have clinical and diagnostic significance in patients with migraine? Can this enlargement be explained by inflammatory mechanisms? Actually, this is the main question to be answered. We could not find any study in the literature that could answer this question. Additional research is needed to describe in more detail the association between migraine and white matter structures.

Funding: None

\section{Conflict of Interest: None}

The study was approved by the Afyonkarahisar Health Sciences University Clinical Research Ethics Committee. 


\section{REFERENCES}

BURING, J.E., HEBERT, P., ROMERO, J., KITTROSS, A., COOK, N., MANSON, J., et al. (1995). Migraine and subsequent risk of stroke in the physicians' health study. Arch Neurol, 52(2), 129-134.

CHANG, C.L., DONAGHY, M. \& POULTER, N. (1999). Migraine and stroke in young women: case-control study: The World Health Organisation collaborative study of cardiovascular disease and steroid hormone contraception. BMJ, 318, 13-18.

CHOWDHURY, F., HAQUE, M., SARKAR, M., ARA, S. \& ISLAM, M. (2010). White fiber dissection of brain; the internal capsule: a cadaveric study. Turk Neurosurg, 20, 314 322 .

DEL ZOTTO, E., PEZZINI, A., GIOSSI, A., VOLONGHI, I. \& PADOVANI, A. (2008). Migraine and ischemic stroke: a debated question. journal of cerebral blood flow and metabolism: official journal of the International Society of Cerebral Blood Flow and Metabolism; 28(8), 1399-1421.

ERTAS, M., BAYKAN, B., ORHAN, E.K., ZARIFOGLU, M., KARLI, N., SAIP, S. et al. (2012). One-Year prevalence and the impact of migraine and tension-type headache in turkey: a nationwide home-based study in adults. The Journal of Headache and Pain, 13(2), 147-157.

EVANS, R.W., BURCH, R.C., FRISHBERG, B.M., MARMURA, M.J., MECHTLER, L.L., SILBERSTEIN, S.D., TURNER, D.P. (2020). Neuroimaging for migraine: the American headache society systematic review and evidence-based guideline. Headache, 60(2), 318-336.

FRAZIER, T.W. \& HARDAN, A.Y. (2009). A meta-analysis of the corpus callosum in autism. Biol Psychiatry, 66(10), 935-941.

GAZZANIGA, M.S. (2000). Cerebral specialization and interhemispheric communication: Does the CC enable the human condition? Brain, 123(7), 1293-1326.

HOFER, S. \& FRAHM, J. (2006). Topography of the human corpus callosum revisitedcomprehensive fibre tractography using diffusion tensor magnetic resonance imaging. Neuroimage, 32(3), 989-994.

HYETT, M.P., PERRY, A., BREAKSPEAR, M., WEN, W. \& PARKER, G.B. (2018). White Matter Alterations in the Internal Capsule and Psychomotor Impairment in Melancholic Depression. PLoS One; 13(4): e0195672.

LEONARDI, M., STEINER, T.J., SCHER, A.T. \& LIPTON, R.B. (2005). The global burden of migraine: measuring disability in headache disorders with WHO's classification of functioning, disability and health (ICF). The Journal of Headache and Pain, 6(6), 429440.

LONGSTRETH, WT J.R., MANOLIO, T.A., ARNOLD, A., BURKE, G.L., BRYAN, N., JUNGREIS, C.A., ENRIGHT, P.L., O'LEARY, D. \& FRIED, L. (1996). Clinical correlates of white matter findings on cranial magnetic resonance imaging of 3301 elderly people. The Cardiovascular Health Study. Stroke, 27(8):1274-1282.

LIPTON, R.B., STEWART, W.F., DIAMOND, S., DIAMOND, M.L. \& REED, M. (2001). Prevalence and burden of migraine in the United States: Data from the American Migraine Study II. Headache, 41(7), 646-657. 
LIPTON, R.B. \& BIGAL, M.E. (2005). Migraine: epidemiology, impact, and risk factors for progression. Headache, 45 Suppl 1, S3-s13.

LIPTON, R.B., BIGAL, M.E., DIAMOND, M., FREITAG, F., REED, M.L. \& STEWART, W.F. (2007). Migraine prevalence, disease burden, and the need for preventive therapy. Neurology; 68(5):343-349.

MATHARU, M.S., GOOD, C.D., MAY, A., BAHRA, A. \& GOADSBY, P.J. (2003). No change in the structure of the brain in migraine: a voxel-based morphometric study. Eur J Neurol, 10(1), 53-57.

OVER, F., BICAKCI, S., SARICA, Y. \& SERTDEMIR, Y. (2007). Beyaz cevher lezyonları ve migren. Türk Nörol Derg; 13, 201-206.

PALM-MEINDERS, I.H., KOPPEN, H., TERWINDT, G.M, et al. (2012). Structural brain changes in migraine. JAMA, 308(18), 1889-1897.

QUIGLEY, M., CORDES, D., TURSKI, P., et al. (2003). Role of the corpus callosum in functional connectivity. AJNR Am J Neuroradiol, 24(2), 208-212.

ROPPER, A.H. \& SAMUELS, M.A. (2011). Adams and Victor's Principles of Neurology. Çeviri editörü: Murat Emre.

RUSSELL, M., IVERSEN, H.K. \& OLESEN, J. (1994). Improved description of the migraine aura by a diagnostic aura diary. Cephalalgia, 14(2), 107-117.

SCHER, AI., GUDMUNDSSON, LS., SIGURDSSON, S. et al. (2009). Migraine headache in middle age and late-life brain infarcts. JAMA, 301(24), 2563-2570.

SCHMITZ, N., ADMIRAAL-BEHLOUL, F., ARKINK E.B. et al. (2008). Attack frequency and disease duration as indicators for brain damage in migraine. Headache: The Journal of Head and Face Pain. 48(7),1044-1055.

SWARTZ, R.H. \& KERN, R.Z. (2004). Migraine is associated with magnetic resonance imaging white matter abnormalities: A meta-analysis. Arch Neurol, 61(9), 1366-1368.

TURAMANLAR, O., BILIR, A., HORATA, E., ERTEKIN, T., OZER GOKASLAN, Ç. \& EMEKSIZ, H. (2020). Morphometry of the internal capsule on MR images in adult healthy individuals. Anatomy, 14(1), 49-52.

UNLU, E., BAGCIOGLU, E., ACAY, M.P. et al. (2014). Magnetic resonance imaging study of corpus callosum abnormalities in patients with different subtypes of schizophrenia. S Afr J Psychiatr, 20(4), 146-152.

WILTSHIRE, K., FOSTER, S., KAYE, J.A., SMALL, B.J., CAMICIOLI, R. (2005). Corpus callosum in neurodegenerative diseases: findings in Parkinson's disease. Dement Geriatr Cogn Disord, 20(6), 345-351. 